\title{
ANALISIS PENGENDALIAN BIAYA PRODUKSI (Studi Kasus Pada PT. TROPICA COCOPRIMA)
}

\author{
Oleh: \\ Paula C. A. Rotinsulu \\ David P.E. Saerang \\ Dhullo Affandi \\ Fakultas Ekonomi dan Bisnis, Jurusan Akuntansi \\ Universitas Sam Ratulangi Manado \\ email: paulaclaudia@ymail.com
}

\begin{abstract}
ABSTRAK
Pergerakkan kemajuan perusahaan di nilai dari kesanggupan perusahaan dapat bertahan didalam persaingan bisnis yang sangat ketat untuk itu perlu adanya pengelolan biaya yang baik yaitu dengan cara mengendalikan biaya. PT. Tropica Cocoprima adalah perusahaan manufaktur yang menghasilkan produk tepung kelapa sebagai hasil akhir dari proses produksi, yang dapat bertahan dalam persaingan. Dalam kegiatan proses produksinya, biaya produksi merupakan faktor yang sangat mempengaruhi dalam segala aspek, oleh karena itu pengendalian biaya produksi merupakan salah satu tolak ukur sebagai pemicu kemajuan kinerja perusahaan. Penelitian ini bertujuan untuk menganalisis efisiensi pengendalian biaya produksi di PT. Tropica Cocoprima. Dengan menggunakan analisis varians diperoleh bahwa pengendalian biaya sudah memadai karena dapat dikaregorikan favorable (menguntungkan) secara keseluruhan. Secara signifikan pada bahan baku di bulan november 2012 dapat diperoleh realisasi rataan sebesar Rp.901/kg, dan berdasarkan analisis varians, varians yang terjadi sebesar Rp. 30.950 .716 dengan rataan presentase varians sebesar 27,9\% dan dapat dikategorikan Favorable (F) atau menguntungkan.
\end{abstract}

Kata kunci: biaya produksi, pengendalian biaya

\begin{abstract}
The movement of the improvement is valued from the capacity of the enterteinment wich can endure in the verry stiff business competition, that is why it needs a good management cost by managing the cost. PT. Tropica Cocoprima is a manufacturing firm producing coconut flour as the final product of the production process that can endure in competition. In the production process activity, the production cost is a factor most influencing in every aspects, and that is why the production cost control measuring standard as the cock of the performance progress of the firm managerial. The goal of this research is to an analyze the efficiency of the controlling production cost at PT. Tropica Cocoprima. By using analysis variance we can get that the cost control is sufficient because it can be categorized over all favorable. Raw material in November 2012 significantly can be found that the realization of the cost wa Rp. $901 / \mathrm{kg}$, and according to analysis variance was Rp. 30.950.716, at the average of $27,9 \%$ and it can be kategorizied as favorable.
\end{abstract}

Keywords: Production cost, cost controll. 


\section{Latar Belakang}

\section{PENDAHULUAN}

PT. Tropica Coco Prima merupakan perusahaan manufaktur atau perusahaan pabrikasi yang mengelolah bahan pokok yang terbuat dari bahan baku yaitu kelapa biji. Perusahaan ini mengelolah kelapa biji menjadi tepung. Pada dasarnya pengeluaran perusahaan mengikuti alur produksi, biaya yang tidak terkontrol pasti akan sangat merugikan perusahaan. Apalagi untuk perkembangan perusahaan di tengah persaingan yang cukup besar, begitu juga dengan bahan baku yang tidak terkontrol pemasukannya pasti akan membuat perusahaan bergerak lambat untuk mencapai tujuan bisnis dan keberlangsungannya (going concern) .

PT. Tropica Coco Prima bergerak dalam bisnis bahan pokok yang bergerak dibidang eksport. Untuk dalam negeri mereka hanya bekerja sama dengan beberapa kalangan bisnis dan sangat terbatas. Oleh karena itu pengendalian biaya sangat dibutuhkan agar tidak terjadi bisnis yang gagal apalagi kerja sama yang gagal antara produsen dan pelanggan, oleh karena perusahaan ini bergerak di bidang bahan pokok tepung yang terbuat dari kelapa biji.

Pengendalian biaya yang memadai akan memberi keuntungan bagi perusahaan. Secara garis besar pengendalian biaya di perusahaan ini berdasarkan pada pengeluaran biaya produktivitas yang ada, jadi dalam periode tertentu perusahaan menekan biaya dengan membuat tolak ukur biaya dan mengakumulasi biaya. Seperti pada bahan baku, tenaga kerja langsung dan biaya-biaya lain.

\section{Tujuan Penelitian}

Tujuan penelitian ini yaitu untuk menganalisis efisiensi pengendalian biaya produksi di PT. Tropica Coco Prima.

\section{Definisi Biaya}

\section{TINJAUAN PUSTAKA}

Hansen dan Mowen (2009), biaya adalah kas atau nilai ekuivalen kas yang dikorbankan untuk mendapatkan barang atau jasa yang diharapkan memberi manfaat saat ini atau di masa yang akan datang bagi organisasi. Simamora (2012) menyatakan biaya adalah kas atau setara kas yang dikorbankan (dibayarkan) untuk barang atau jasa yang diharapkan memberikan manfaat (pendapatan) pada saat ini atau di masa depan bagi perusahaan.

\section{Pengertian Biaya produksi}

Mulyadi (2009) menyatakan bahwa, Biaya produksi adalah biaya-biaya yang terjadi untuk mengolah bahan baku menjadi produk jadi yang siap untuk dijual. Biaya produksi juga merupakan biaya yang melekat pada atau berhubungan dengan produk, Krismaji dan Aryani (2011).

\section{Unsur Biaya produksi}

Jenis-jenis biaya produksi menurut Samryn (2012) adalah sebagai berikut :

1. Biaya bahan langsung, yang terdiri dari bahan-bahan baku yang menjadi bagian yang integral dari produksi jadi dan dapat diteluuri hubungannya dengan mudah ke dalam produk yang dihasilkan. Misalnya untuk membuat sebuah meja kayu sederhana, secara fisik bahan baku kayu dapat dilihat dengan mudah sebagai komponen produk yang dihasilkan.

2. Biaya tenaga kerja langsung, yang terdiri dari biaya-biaya tenaga kerja pabrik yang dapat ditelusuri hubungannya dengan mudah ke dalam produk-produk tertentu. Biaya ini juga sering disebut touched labor karena biaya ini dibayarkan kepada para pegawai atau buruh yang secara langsung melaksanakan proses produksi biaya ini terjadi karena adanya penggunaan tenaga kerja dalam proses produksi.

3. Biaya overhead pabrik meliputi semua biaya yang berhubungan dengan pabrik selain bahan langsung dan tenaga kerja langsung.

\section{Konsep Pengendalian}

Pengendalian dibutuhkan dalam setiap pekerjaan untuk mengevaluasi kegiatan yang telah dilakukan agar sesuai dengan yang direncanakan semula. Hansen dan Mowen (2009) menyatakan Pengendalian adalah melihat ke belakang, memutuskan apakah yang sebenarnya telah terjadi dan membandingkannya dengan hasil yang direncanakan sebelumnya. Pengendalian di capai dengan membandingkan hasil aktual dengan hasil biaya secara periodik. 


\section{Pengendalian Biaya}

Mulyadi (2007) menyebutkan pengendalian biaya mencakup dalam arti luas juga penurunan biaya. Tetapi, dalam arti sempit, pengendalian biaya dapat dianggap sebagai usaha manajemen untuk memperoleh sasaran biaya dalam lingkungan operasi tertentu.

Mulyadi (2009) mengungkapkan bahwa dalam pengendalian biaya ada yang dengan menggunakan biaya standar dan ada juga yang menggunakan taksiran biaya.

\section{Pengendalian Biaya produksi Dengan Biaya Standar}

Witjaksono (2013) menyatakan bahwa biaya Standar adalah patok duga (bencmark) yang secara efektif dan efisien ditetapkan dimuka untuk biaya-biaya yang seharusnya dikonsumsi oleh suatu produk.

Mursyidi (2010) Manfaat biaya standar adalah sebagai berikut (Mursyidi:

1. Penetapan harga. Proses penganggaran akan lebih cepat, dan reliabel apabila menggunakan biaya standar. Cepat, karena penentuan volume yang lebih rinci dan harga yang lebih kurat sudah tersedia; reliabel, karena, anggaran disusun secara rinci dengan menggunkan hasil analisis atas biaya yang telah terjadi, dengan memperlihatkan efisiensi dan penyebab terjadinya selisih.

2. Pengendaliam biaya. Sistem biaya standar memberikan motivasi kepada para tenaga kerja, karena tingkat efisiensi akan dan dapat diukur, sehingga dapat ditetapkan tingkat kinerja yang baik. Melalui analisis selisih, biaya akan dihitung dan diukur tingkat efisiensi, sehingga dapat mengetahui efektifitas tenaga kerja, mana yang lebih memperhatikan sasaran pembiayaan dan mana yang tidak.

3. Penyederhanaan prosedur dan pelaporan biaya. Sistem biaya standar akan menguraki pekerjaan klerikal. Kalkulasi biaya dapat dilakukan secara otomatis dan lebih cepat diperoleh datanya; dan secara segera dapat dibuat dan disajikan laporannya, sehingga ekspedisi dapat segera dilakukan.

4. Penetapan harga pokok bahan, barang dalam proses dan barang jadi. Umumnya perusahaan tidak menggunakan biaya standar untuk menentukan harga pokok persediaan-persediaan tersebut. Tetapi sistem biaya standar akan memberikan panduan yang dapat meningkatkan efisiensi dan akurasi dalam pekerjaan klerikal akuntansi.

5. Dasar untuk melakukan kontrak dan penetapan harga.

\section{Pengendalian Biaya produksi Dengan Biaya Taksiran}

Mulyadi (2009) menyatakan bahwa biaya taksiran (estimated cost) merupakan salah satu bentuk biaya yang ditentukan di muka sebelum di produksi di lakukan atau penyerahan jasa dilaksanakan. Sistem biaya taksiran adalah sistem akuntansi biaya produksi yang menggunakan suatu bentuk biaya-biaya yang ditentukan di muka dalam menghitung harga pokok produk yang diproduksi.

Mulyadi (2009) mengungkapkan pula bahwa penentuan biaya taksiran dipecah menjadi tiga unsur: biaya bahan baku, biaya tenaga kerja, dan biaya overhead pabrik. Biaya taksiran dapat ditentukan atas dasar data masa lalu, dari perhitungan, dari rumus kimia atau matematis, atau secara sderhana dengan taksiran. Biaya taksiran ditentukan untuk setiap jenis produkyang diproduksi, pada awal masa produksi atau pada awal tahun anggaran.

\section{Analisis Varians}

Varians atau selisih adalah perbedaan antara suatu rencana atau target dan suatu hasil. Varian memberikan indikasi atau suatu peringatan bahwa operasi tidak berjalan sebagaimana yang direncanakan. Analisis varian adalah melakukan dekomposisi atas perbedaan-perbedaan antara biaya aktual dan rencana menjadi jumlah-jumlah yang terkait pada suatu realitas dan rencana. (Witjaksono:2013) 
Peneltian Terdahulu

Tabel 1. Penelitian Terdahulu

\begin{tabular}{|c|c|c|c|c|c|c|}
\hline $\begin{array}{l}\text { Nama } \\
\text { Peneliti/ } \\
\text { Tahun }\end{array}$ & Judul & Tujuan & $\begin{array}{l}\text { Metode } \\
\text { Penelitian }\end{array}$ & $\begin{array}{l}\text { Hasil } \\
\text { Penelitian }\end{array}$ & Persamaan & Perbedaan \\
\hline $\begin{array}{l}\text { Pamungkas } \\
\text { dan Afrianti } \\
(2006)\end{array}$ & $\begin{array}{l}\text { Evaluasi Akuntansi } \\
\text { Pertanggungjawaban } \\
\text { sebagai alat bantu } \\
\text { manajemen dalam } \\
\text { pengendalian biaya } \\
\text { (Studi Kasus pada } \\
\text { PT. Cahaya Buana } \\
\text { Intitama) }\end{array}$ & & Deskriptif & $\begin{array}{l}\text { Untuk biaya bahan } \\
\text { baku menggunakan } \\
\text { unit ratio, sehingga } \\
\text { dapat memudahkan } \\
\text { penentuan harga } \\
\text { jual per unit, tetapi } \\
\text { batasan untuk } \\
\text { menetukan efisiensi } \\
\text { digunakan analisis } \\
\text { varians. } \\
\text { Membandingkan } \\
\text { anggaran dan } \\
\text { realisasinya. }\end{array}$ & $\begin{array}{l}\text { Memiliki } \\
\text { salah satu } \\
\text { variabel } \\
\text { penelitian } \\
\text { yang sama } \\
\text { yaitu } \\
\text { pengendalian } \\
\text { biaya }\end{array}$ & $\begin{array}{l}\text { Peneliti yang } \\
\text { sebelumnya } \\
\text { mengambil } \\
\text { menggunakan } \\
\text { akuntansi } \\
\text { pertanggungjaw } \\
\text { aban sebagai } \\
\text { alat } \\
\text { pengendalian } \\
\text { biaya. }\end{array}$ \\
\hline
\end{tabular}

Sumber: Berbagai sumber yang diolah

Jenis Penelitian

\section{METODE PENELITIAN}

Jenis penelitian ini merupakan penelitian deskriptif. Penelitian deskriptif menurut Sekaran dan Bougie (2009) mendefinisikan:

"a descriptive study is undertaken in order to ascertain and be able to describe the characteristics of the variables of interest in a situation".

Peneliti mengumpulkan data, mencari fakta tentang penelitian pada perusahaan, kemudian menjelaskan dan menganalisis data yang diperoleh.

\section{Tempat dan Waktu Penelitian}

Tempat yang menjadi penelitian dari penulis adalah PT. Tropica Coco Prima yang bertempat di Jl. Balai Kota No.12 Manado sebagai Kantor di Manado, dengan pabrik yang berlokasi di Desa Lelema kecamatan Tumpaan Kabupaten Minahasa Selatan. Waktu penelitian yang dilakukan oleh penulis yaitu dari bulan April sampai dengan selesai.

\section{Metode Pengumpulan data}

\section{Jenis Data}

Jenis data yang digunakan penulis pada penelitian skripsi ini adalah data kuantitatif, yaitu laporan perusahaan yang berupa angka-angka seperti laporan-laporan biaya perusahaan dan laporan-laporan sejenis 
yang merupakan hasil perhitungan selama beberapa tahun. Data kuantitatif adalah data yang disajikan dalam bentuk angka-angka. Data kuantitatif adalah data yang diukur dalam suatu skala numerik. (Kuncoro:2009)

2. Sumber Data

a. Data primer merupakan data yang diperoleh dari sumber aslinya. Data primer dalam penelitian ilmiah selain survei yaitu observasi langsung, yaitu proses pencatatan pola perilaku subyek (orang), obyek (benda) atau kejadian yang sistematik tanpa adanya pertanyaan atau komunikasi dengan individu-individu yang diteliti. Data primer merupakan data yang dikumpulkan oleh perorangan atau organisasi perusahaan yang merupakan obyek penelitian dimana data tersebut merupakan data yang belum di olah dan di ambil langsung. Dalam penelitian ini penulis mengambil data langsung dari perusahaan yaitu data hasil laporan keuangan yang berupa hasil laporan perhitungan rugi/laba yang di dalamnya terlampir objek biaya-biaya yang akan diteliti atau analisis, laporan biaya produksi.

b. Data sekunder. Data sekunder adalah data yang telah dikumpulkan oleh pihak lain. (Kuncoro:2009). Data sekunder yang di ambil, diperoleh dari hasil literatur kuliah, makalah, jurnal, majalah, koran, serta literaturliteratur lainnya yang berhubungan dengan penelitian serta referensi lainnya yang relevan dengan penelitian ini. Untuk itu sebagai salah satu bahan dasar untuk penelitian ini, penulis pun mengambil beberapa literatur kuliah dan juga jurnal-jurnal yang terlampir dalam daftar pustaka, begitu juga beberapa referensi lain yang diambil dalam blog atau dengan kecanggihan teknologi masa kini yaitu internet yang merupakan suatu masukan yang relevan bagi skripsi ini.

\section{Teknik Pengumpulan Data}

1. Penelitian lapangan (Field Research) yaitu metode yang dilakukan di lapangan dengan cara wawancara,survei lapangan, observasi atau pengamatan langsung di lokasi penelitian, dan pengambilan data perusahaan yang berhubungan dengan penelitian.

2. Browse Internet, dalam penelitian ini penulis mengambil beberapa data yang merupakan gambaran umum perusahaan yaitu bagaimana keadaan perusahaan secara keseluruhan, dan perkembangan perusahaan melalui internet.

\section{Metode Analisis Data}

Metode yang digunakan dalam menganalisis data adalah metode deskriptif dimana metode ini membahas permasalahan yang sifatnya menguraikan, menggambarkan dan melukiskan suatu data atau keadaan sedemikian rupa sehingga ditarik suatu kesimpulan untuk menjawab permasalahan yang ada. Analisis yang dipakai dalam penelitian ini adalah analisis varians yaitu membandingkan biaya yang terealisasi dengan biaya yang telah dianggarkan perusahaan.

\section{Gambaran Objek Penelitian}

\section{HASIL PENELITIAN DAN PEMBAHASAN}

PT Tropica Cocoprima merupakan perusahaan yang memproduksi tepung kelapa yang berkualitas yang sudah memiliki penghargaan mengenai kualitas tepungnya. PT.Tropica Cocoprima dibangun pada tahun 1997 dan memulai operasi komersial pada bulan Mei 1998. Perusahaan memiliki laboratorium sendiri, Visi PT. Tropica Cocoprima adalah untuk dikenal dan diakui sebagai salah satu penghasil (produsen) Tepung Kelapa yang berkualitas. Sedangkan Misi PT. Tropica Cocoprima adalah Perusahaan berkomitmen untuk menjadi pemasok produk Tepung Kelapa yang terbaik dan berkualitas tinggi kepada para konsumen dan dengan proses yang menguntungkan. Perusahaan pun selalu melakukan pengujian baik bahan baku dan produk jadi dilakukan secara profesional. Lokasi Pabrik PT. Tropica Cocoprima dimana kegiatan proses produksinya dijalankan pada saat ini berlokasi di Desa Lelema Kecamatan Tumpaan, Kabupaten Minahasa Selatan Provinsi Sulawesi Utara.

\section{Hasil Penelitian}

\section{Metode Pengumpulan Biaya Produksi Yang Digunakan PT. Tropica Cocoprima.}

PT. Tropica Coco Prima menggunakan metode harga pokok pesanan atau Job Order Costing. Pada dasarnya PT. Tropica Coco Prima memproduksi produk berdasarkan pesanan dari pelanggan sesuai dengan jenis tepung kelapa yang dimintakan oleh pelanggan. Secara keseluruhan jenis permintaan atau pesanan yang tetap adalah jenis Medium dengan ukuran $100 \mathrm{lbs}$ atau 45,36 kg. Sesuai dengan metode job order costing biaya produksi digolongkan berdasarkan hubungannya dengan produk menjadi dua kelompok berikut ini yaitu biaya produkusi langsung dan biaya produksi tidak langsung. Biaya produksi langsung terdiri dari biaya bahan baku 
dan biaya tenaga kerja langsung, sedangkan biaya produksi tidak langsung disebut dengan istilah biaya overhead pabrik.

\section{Penggolongan Biaya Produksi Pada PT. Tropica Cocoprima}

Data mengenai biaya produksi di PT. Tropica Coco Prima meliputi biaya bahan baku langsung, biaya tenaga kerja langsung, dan biaya overhead pabrik. PT. Tropica coco Prima memproduksi tepung kelapa dengan berbagai macam jenis dan ukuran seperti Medium, Fine, Extra Fine, ada juga jenis khusus seperti Fancy Shred, dan Chips, jenis tepung kelapa yang sangat halus.

\section{Biaya Bahan Baku Langsung}

Tabel 2. PT. Tropica Cocoprima Laporan Biaya Bahan Baku Aktual Per Januari 2012-31 Desember 2012

\begin{tabular}{|l|l|l|}
\hline Bulan & $\begin{array}{l}\text { Berat Bersih } \\
\text { (kg) }\end{array}$ & Jumlah (Rp) \\
\hline Januari & 722.153 & 863.619 .440 \\
Februari & 1.243 .901 & 1.576 .569 .430 \\
Maret & 1.762 .442 & 2.359 .146 .595 \\
April & 1.927 .170 & 2.549 .832 .000 \\
Mei & 1.769 .205 & 2.115 .616 .330 \\
Juni & 1.769 .962 & 1.821 .130 .365 \\
Juli & 1.028 .501 & 946.983 .495 \\
Agustus & 1.559 .270 & 1.424 .151 .075 \\
September & 1.481 .671 & 1.312 .539 .935 \\
Oktober & 1.544 .461 & 1.470 .910 .590 \\
November & 1.862 .368 & 1.678 .129 .190 \\
Desember & 1.503 .098 & 1.227 .951 .195 \\
\hline Total & 18.174 .202 & 19.346 .579 .640 \\
\hline
\end{tabular}

Tabel 3. Laporan Biaya Produksi PT.Tropica Cocoprima Per Januari 2012-31 Desember 2012

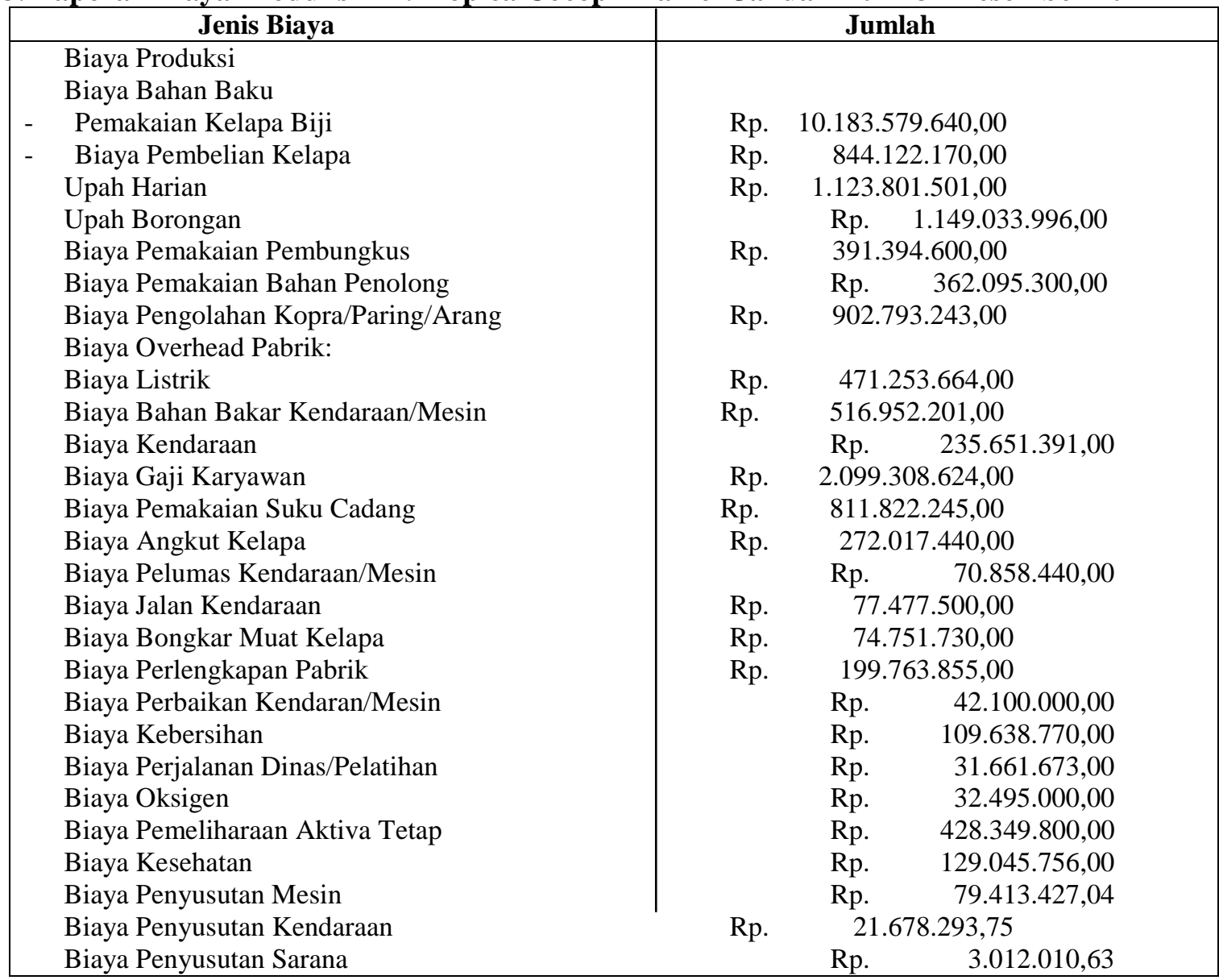




\begin{tabular}{|l|rr|}
\hline Biaya Penyusutan Peralatan Pabrik/Laboratorium & Rp. & $7.559 .470,26$ \\
Biaya Penyusutan Bangunan & Rp. & $4.391 .452,62$ \\
\cline { 2 - 2 } Total Biaya Produksi & Rp. & $\mathbf{2 0 . 6 7 6 . 0 8 3 . 2 3 3 , 3 0}$ \\
\hline
\end{tabular}

\section{Analisis Pengendalian Biaya Produkusi pada PT. Tropica Cocoprima}

Umumnya perusahaan dapat menggunakan sistem penentuan biaya untuk pengendalian biaya yakni sistem biaya standar atau sistem biaya historis. PT. Tropica Coco Prima menggunakan sistem biaya standar dan biaya taksiran dalam penentuan biayanya sebagai alat pengendalian biaya. Penetapan standar taksiran biaya merupakan alat pengendalian biaya produksi yang di pakai oleh perusahaan.

\section{Analisis Varians}

Pengendalian biaya produksi apakah sudah memadai dengan kata lain sudah efisien atau belum efisien dapat diperoleh melalui analisis varians.

Tabel 4. PT. Tropica Cocoprima Analisis Varians Rata-rata harga Bahan Baku Langsung Per Januari-31 Desember 2012

\begin{tabular}{|c|c|c|c|c|c|c|c|}
\hline \multirow[b]{2}{*}{ Bulan } & \multirow[b]{2}{*}{$\begin{array}{c}\text { Nama } \\
\text { Bahan } \\
\text { Baku }\end{array}$} & \multicolumn{4}{|c|}{ Analisis Varians Rata-rata Harga Bahan Baku (Rp) } & \multirow[b]{2}{*}{$\mathbf{U} / \mathbf{F}$} & \multirow[b]{2}{*}{ Varians } \\
\hline & & $\begin{array}{c}\text { Standar } \\
\text { Harga } \\
\text { (SP) } \\
\end{array}$ & $\begin{array}{c}\text { Realisasi } \\
\text { Harga } \\
\text { (AP) }\end{array}$ & $\begin{array}{c}\text { Kuantitas } \\
\text { Aktual } \\
\text { (AQ) } \\
\end{array}$ & $\begin{array}{l}\text { Analisis } \\
\text { Varians } \\
\text { (MPV) }\end{array}$ & & \\
\hline Januari & Kelapa & 1.250 & $1.158,60$ & 80.239 & 7.333 .845 & $\mathrm{~F}$ & $7,32 \%$ \\
\hline Februari & Kelapa & 1.250 & $1.267,50$ & 62.195 & 1088412,5 & $\mathrm{U}$ & $1,40 \%$ \\
\hline Maret & Kelapa & 1.250 & $1.338,60$ & 83.925 & 7435755 & $\mathrm{U}$ & $7,09 \%$ \\
\hline April & Kelapa & 1.250 & 1.323 & 87.598 & 6394654 & $\mathrm{U}$ & $5,84 \%$ \\
\hline Mei & Kelapa & 1.250 & 1.196 & 80.418 & -4358656 & $\mathrm{~F}$ & $4,34 \%$ \\
\hline Juni & Kelapa & 1.250 & 1.029 & 84.283 & $18626543^{-}$ & F & $17,68 \%$ \\
\hline Juli & Kelapa & 1.250 & 920 & 93.500 & 30855000 & F & $26,40 \%$ \\
\hline Agustus & Kelapa & 1.250 & 913 & 74.251 & 25022587 & F & $26,96 \%$ \\
\hline September & Kelapa & 1.250 & 886 & 92.604 & 33717116 & F & $21,7 \%$ \\
\hline Oktober & Kelapa & 1.250 & 952 & 81.287 & 24191011 & F & $23,8 \%$ \\
\hline November & Kelapa & 1.250 & 901 & 88.684 & 30950716 & F & $27,9 \%$ \\
\hline Desember & Kelapa & 1.250 & 817 & 93.943 & 40677319 & $\mathrm{~F}$ & $34,64 \%$ \\
\hline
\end{tabular}

Tabel diatas menunjukkan standar harga bahan baku langsung kelapa pada tahun 2012 mulai dari bulan Januari-Desember sebesar Rp.1250/kg dengan rataan realisasi sebesar Rp.1.158,6/kg. Berdasarkan hasil analisis varians, varians yang terjadi pada sebesar Rp. 7.381.988,- dengan rataan presentase varians sebesar 7,32\% yang dapat diketegorikan Favorable (F) atau menguntungkan, pada bulan Januari. Sedangkan berdasarkan tabel diatas pada bulan berikutnya terjadi peningkatan harga secara aktual. Pada bulan Februari, dengan rataan realisasi sebesar Rp. 1.267,5/kg. Berdasarkan analisis varians, varians yang terjadi sebesar Rp. 1.088.412,dengan rataan presentase varians sebesar $1,40 \%$ yang dapat di kategorikan Unfavorable (U) atau tidak menguntungkan. Karena melebihi standar harga perusahaan. Pada bulan berikutnya bulan Maret, dengan rataan realisasi sebesar Rp. 1338,6/kg. berdasarkan analisis varians, varians yang terjadi sebesar Rp. 7.435.755,dengan rataan presentase varians sebesar $7,09 \%$ yang dapat diketegorikan Unfavorable (U) atau tidak menguntungkan. Pada bulan April, dengan rataan realisasi sebesar Rp. 1.323/kg. Berdasarkan analisis varians, varians yang terjadi sebesar Rp. 6.394.654,- dengan rataan presentase varians sebesar $5,84 \%$ yang dapat dikategorikan Unfavorable (U) atau tidak menguntungkan, kerena melebihi standar harga perusahaan. Tetapi pada bulan berikutnya berdasarkan tabel yang ada, terjadi penurunan harga bahan baku mulai dari bulan Mei 
hingga Desember. Hal ini menyebabkan keuntungan yang sudah terealisasi bagi perusahaan. Berdasarkan tabel ini, pada bulan Mei dengan rataan realisasi sebesar Rp. 1195,8/kg. Dengan berdasarkan analisis variannya, varians yang terjadi sebesar Rp. 4.358.655,6 dengan rataan presentase varians sebesar 4,34\% yang dapat di kategorikan Favorable (F) atau menguntungkan, karena harga aktual tersebut kurang dari standar yanf ditetapkan oleh perusahaan. Berikutnya bulan Juni, dengan rataan realisasi sebesar Rp.1.029/kg. Berdasarkan analisis varians, varians yang terjadi sebesar Rp. 18.626.43 dengan rataan presentase varians sebesar 17,68\% yang dapat dikategorikan Favorable (F) atau menguntungkan. Pada bulan Juli, dengan ratan realisasi sebesar Rp. 920/kg. Berdasarkan analisis varians, varians yang terjadi sebesar Rp. 30.855 .000 dengan rataan presentase varians sebesar 26,40\% yang dapat diketegorikan Favorable (F) atau menguntungkan, karena harga aktualnya kurang dari standar harga perusahaan. Berikutnya pada bulan Agustus dengan rataan realisasi sebesar Rp. 913/kg berdasarkan analisis varians, varians yang terjadi sebesar Rp. 25.022.587,- dengan rataan presentase varians sebesar 26,96\% yang dapat di kategorikan Favaorable (F) atau menguntungkan.

Tabel 5. PT. Tropica Cocoprima Analisis Varians Rata-rata Efisiensi Bahan Baku Langsung Per Januari-31 Desember 2012

\begin{tabular}{|c|c|c|c|c|c|c|c|}
\hline \multirow[b]{2}{*}{ Bulan } & \multirow[b]{2}{*}{$\begin{array}{c}\text { Nama } \\
\text { Bahan } \\
\text { Baku }\end{array}$} & \multicolumn{4}{|c|}{ Analisis Varians Rata-rata Efisiensi Bahan Baku (Kg) } & \multirow[b]{2}{*}{$\mathbf{U} / \mathbf{F}$} & \multirow[b]{2}{*}{ Varians } \\
\hline & & $\begin{array}{c}\text { Standar } \\
\text { Kuantitas } \\
\text { (SQ) }\end{array}$ & $\begin{array}{c}\text { Realisasi } \\
\text { Kuantitas } \\
\text { (AQ) }\end{array}$ & $\begin{array}{c}\text { Standar } \\
\text { Harga } \\
\text { (SP) }\end{array}$ & $\begin{array}{l}\text { Analisis } \\
\text { Varians } \\
\text { (MUV) }\end{array}$ & & \\
\hline Januari & Kelapa & 85.000 & 80.239 & 1.250 & -5951250 & $\mathrm{~F}$ & $5,6 \%$ \\
\hline Februari & Kelapa & 85.000 & 62.195 & 1.250 & 28506250 & $\mathrm{~F}$ & $26,83 \%$ \\
\hline Maret & Kelapa & 85.000 & 83.925 & 1.250 & -1343750 & $\mathrm{~F}$ & $1,27 \%$ \\
\hline April & Kelapa & 85.000 & 87.598 & 1.250 & 3247500 & $\mathrm{U}$ & $3,06 \%$ \\
\hline Mei & Kelapa & 85.000 & 80.418 & 1.250 & -5727500 & $\mathrm{~F}$ & $5,39 \%$ \\
\hline Juni & Kelapa & 85.000 & 84.283 & 1.250 & -896250 & $\mathrm{~F}$ & $0,85 \%$ \\
\hline Juli & Kelapa & 85.000 & 93.500 & 1.250 & 10625000 & $\mathrm{U}$ & $-10,00 \%$ \\
\hline Agustus & Kelapa & 85.000 & 74.251 & 1.250 & 13436250 & $\mathrm{~F}$ & $12,65 \%$ \\
\hline September & Kelapa & 85.000 & 92.604 & 1.250 & 9505000 & $\mathrm{U}$ & $8,95 \%$ \\
\hline Oktober & Kelapa & 85.000 & 81.287 & 1.250 & -4641250 & $\mathrm{~F}$ & $4,37 \%$ \\
\hline November & Kelapa & 85.000 & 88.684 & 1.250 & 4605000 & $\mathrm{U}$ & $4,34 \%$ \\
\hline Desember & Kelapa & 85.000 & 93.943 & 1.250 & 11178750 & $\mathrm{~F}$ & $10,53 \%$ \\
\hline
\end{tabular}

Tabel 5 menujukkan, standar efisiensi bahan baku langsung kelapa selama tahun 2012 dari bulan JanuariDesember memiliki rataan sebesar $85.000 \mathrm{~kg}$ per hari per produksi. Pada bulan Januari, memiliki rataan realisasi sebesar 85.239,3 kg per hari per produksi. berdasarkan hasil analisis varians, varians yang terjadi sebesar Rp. 5.951.250,- dengan rataan presentase varians sebesar 5,6\% yang dapat dikategorikan Favorable (F) atau menguntungkan. Pada bulan Februari terjadi penurunan kuantitas, dibandingkan dengan bulan Januari. Pada bulan ini, dengan rataan realisasi sebesar $62.195 \mathrm{~kg}$ per produksi per hari. Berdasarkan hasil analisis varians, varians yang terjadi sebesar Rp.28.506.250 dengan ratan presentase varians sebesar $26,83 \%$ yang dapat dikategorikan Favorable (F) atau menguntungkan. Pada bulan berikutnya bulan Maret, dengan rataan realisasi sebesar 80.925,8 kg per produksi per hari. Berdasarkan hasil analisis varians, varians yang terjadi sebesar Rp. 28.506.250 dengan rataan presentase varians sebesar 1,27\% yang dapat dikategorikan Favorable (F) atau menguntungkan. Pada bulan berikutnya bulan April, dengan rataan realisasi sebesar 87.598,7 kg per produksi per hari. Berdasarkan hasil analisis varians, varians yang terjadi sebesar Rp. 3.247.500 dengan rataan presentase varians sebesar. 3,06 \% yang dapat dikategorikan Favorable (F) atau menguntungkan. Pada bulan berikutnya bulan Mei, dengan rataan realisasi sebesar $80.418,4 \mathrm{~kg}$ per produksi per hari. Berdasarkan hasil analisis varians, varians yang terjadi sebesar Rp. 5.727.500 dengan rataan presentase varians sebesar 5,39\% yang dapat dikategorikan Favorable (F) atau menguntungkan. Pada bulan Juni, dengan rataan realisasi sebesar 84.283,9 kg 
per produksi per hari. Berdasarkan hasil analisis varians, varians yang terjadi sebesar Rp. 896.250 dengan rataan presentase varians sebesar 0,85\% yang dapat dikategorikan Favorable (F) atau menguntungkan. Pada bulan Juli terjadi kenaikan kuantitas bahan baku yaitu dengan rataan realisasi sebesar $93.500 \mathrm{~kg}$ per produksi per hari. Berdasarkan hasil analisis varians, varians yang terjadi sebesar Rp. 10.625.000 dengan rataan presentase varians sebesar $10 \%$ yang dapat dikategorikan Unfavorable (U) atau tidak menguntungkan.

Tabel 6. PT. Tropica Cocoprima Analisis Varians Rata-rata Efisiensi Tenaga Kerja Langsung Per Januari-31 Desember 2012

\begin{tabular}{|c|c|c|c|c|c|c|}
\hline \multirow[b]{2}{*}{ Jenis Varians } & \multicolumn{4}{|c|}{ Analisis Varians Rata-rata Efisiensi TKL } & \multirow[b]{2}{*}{$\mathbf{U} / \mathbf{F}$} & \multirow[b]{2}{*}{ Varians } \\
\hline & $\begin{array}{c}\text { Jam } \\
\text { TKL } \\
\text { Standar } \\
\text { (SH) }\end{array}$ & $\begin{array}{c}\text { Jam } \\
\text { TKL } \\
\text { Aktual } \\
\text { (AH) }\end{array}$ & $\begin{array}{c}\text { Tarif Upah } \\
\text { Standar } \\
\text { (SR) }\end{array}$ & $\begin{array}{l}\text { Analisis } \\
\text { Varians }\end{array}$ & & \\
\hline Tarif TKL: & & & & & & \\
\hline Upah Harian(Perer) & 2304 & 2160 & 35,5 & -5112 & $\mathrm{~F}$ & $0,62 \%$ \\
\hline Upah Harian(Sheller) & 2304 & 2160 & 26 & -3744 & $\mathrm{~F}$ & $0,62 \%$ \\
\hline Upah Borongan & 2304 & 2160 & 42.000 & -6048000 & $\mathrm{~F}$ & $0,62 \%$ \\
\hline
\end{tabular}

Berdasarkan tabel diatas jam tenaga kerja langsung aktual per tahun yaitu 2.160 jam, karena jam kerja aktual per orang per hari adalah 7,5 jam. Berarti berdasarkan analisis varians, varians yang terjadi pada upah harian Perer sebesar Rp.5112 dengan presentase varians sebesar 6,2\% dan dikategorikan favorable (F) atau menguntungkan. Varians yg terjadi pada upah harian Sheller sebesar Rp. 3744 dengan presentase varians sebesar 6,2 \% sedangkan pada upah borongan sebesar Rp. 6.048 .000 varians yang terjadi, dengan presentase varians sebesar 6,2\% dan dikategorikan Favorable (F) atau menguntungkan.

\section{Analisis Varians Overhead Pabrik}

Tabel 7. PT. Tropica Cocoprima Per Desember 2012 Analisis Variansi Pengeluaran Overhead Tetap

\begin{tabular}{|c|c|c|c|}
\hline Biaya Overhead Tetap & Biaya Aktual & $\begin{array}{c}\text { Biaya Yang } \\
\text { Dianggarkan }\end{array}$ & $\begin{array}{c}\text { Varians } \\
\text { Pengeluaran }\end{array}$ \\
\hline Biaya Penyusutan Mesin & Rp. $\quad 79.413 .427,04$ & Rp. $\quad 79.413 .427,04$ & 0 \\
\hline Biaya Penyusutan Kendaraan & Rp. $\quad 21.678 .293,75$ & Rp. $\quad 21.678 .293,75$ & 0 \\
\hline Biaya Penyusutan Sarana & $3.012 .010,63$ & $3.012 .010,63$ & 0 \\
\hline Biaya Penyusutan Peralatan Pabrik & $7.559 .470,26$ & $7.559 .470,26$ & 0 \\
\hline Biaya Penyusutan Bangunan & $4.391 .452,62$ & Rp. $\quad 4.391 .452,62$ & 0 \\
\hline Biaya Gaji Karyawan & Rp. 2.099.308.624,00 & Rp. 1.731.330.136,00 & Rp. 367.978 .448 \\
\hline Total & Rp. 2.215.363.278,30 & Rp. 1.847.384.790,30 & Rp. 367.978 .448 \\
\hline
\end{tabular}

Berdasarkan tabel ini dapat diketahui bahwa biaya yang dianggarkan pada overhead tetap ini lebih besar keseluruhan totalnya dibandingkan dengan total aktualnya yaitu total biaya yang dianggarkan sebesar Rp. 1.847.384.790,30 dan total aktual overhead pabrik tetap sebesar Rp. 2.215.363.278,30, dengan hasil total varians sebesar Rp. 367.978.448, maka dapat diketahui bahwa varians ini dikategorikan favorable (F) atau menguntungkan.

Hal ini disebabkan oleh biaya gaji karyawan lebih besar dibandingkan dengan anggaran yang direncanakan. Karena pada tahun 2012, adanya kenaikan gaji karyawan dan tambahan bonus/insentif, serta adanya penambahan karyawan.

\section{Kesimpulan}

\section{PENUTUP}

Berdasarkan penelitian yang dilakukan, maka dapat diambil kesimpulan sebagai berikut: 
1) PT. Tropica Cocoprima telah membuat suatu kebijakan untuk mengendalikan biaya khususnya pada biaya produksi karena berdasarkan analisis varians yang terjadi dikategorikan favorable (menguntungkan). Diantaranya pada harga bahan baku per Januari-31 Desember 2012 secara signifikan yang terjadi yaitu tidak ada varians yang digolongkan merugikan, karena dikategorikan sebagai favorable atau menguntungkan.

2) Perusahaan sudah mengendalikan biaya secara efisien karena diperoleh pada biaya overhead pabrik, perusahaan mengeluarkan lebih sedikit biaya overhead variabelnya daripada kapasitas normalnya, yaitu biaya overhead variabel yang dikeluarkan sebesar Rp. 3.503.899.495 secara aktual sedangkan kapasitas normalnya sebesar Rp. 3.671.449.278 berarti tidak terjadi varians yang merugikan dan dikategorikan favorable atau menguntungkan, dengan begitu secara keseluruhan biaya produksi dapat terkendali dengan memadai karena tidak terjadi penyimpangan-penyimpangan atau biaya yang berlebihan

\section{Saran}

Berdasarkan hasil penelitian yang diperoleh, penulis mengajukan beberapa saran yang mungkin dapat membantu perusahaan di masa mendatang, yaitu sebagai berikut:

1) Perusahaan juga harus memperhatikan cost driver dalam penentuan sistem biaya. Karena cost driver termasuk hal yang penting untuk diketahui.

2) Sebaiknya perusahaan mempertimbangkan dengan menggunakan historis cost sebagai alat pengendalian biaya juga. Karena mungkin dapat membantu perusahaan dalam menanggapi biaya.

3) Pengendalian biaya produksi dalam perusahaan seharusnya lebih difokuskan lagi. Mengingat faktor-faktor tertentu yang dapat memicu biaya pada waktu-waktu tertentu.

\section{DAFTAR PUSTAKA}

Hansen, Don R., Mowen, Maryanne M. 2009. Akuntansi Manajerial. Edisi Kedelapan. (Diterjemahkan oleh: Deny Arnos Kwary). Penerbit Salemba Empat. Jakarta.

Krismaji., Aryani. Y. A. 2011. Akuntansi Manajemen. Edisi Kedua. Penerbit Sekolah Tinggi Ilmu Manajemen YKPN: Yogyakarta.

Kuncoro, M. 2009. Metode Riset. Edisi Ketiga. Erlangga. Jakarta.

Martusa, Riki, dan Marsiana Jennie. 2010. Evaluasi Biaya Standar dalam Pengendalian Biaya Produksi (Studi Kasus pada PT. PG. RAJAWALI SUBANG). Jurnal Bisnis Manajemen \& Ekonomi. Vol. 9, No.11. ISSN: 1693-8305. Universitas Kristen Maranatha. Bandung.

Mulyadi. 2007. Sistem Perencanaan dan Pengendalian Manajemen. Edisi Ketiga. Salemba Empat. Jakarta.

Mulyadi. 2009. Akuntansi Biaya. Edisi Kelima. Penerbit Sekolah Tinggi Ilmu Manajemen YKPN: Yogyakarta.

Mursyidi. 2010. Akuntansi Biaya: Conventional Costing, Just in Time, dan Activity-Based Costing. PT. Refika Aditama. Bandung.

Samryn, L. M. 2012. Akuntansi Manajemen. Edisi Pertama. Penerbit Kencana Prenada Media Group. Jakarta.

Sekaran., Bougie,R. 2009. Research Method For Business: A Skill Building Aproach. John wiley and sons. Ltd. United Kingdom

Simamora, H. 2012. Akuntansi Manajemen. Edisi Ketiga. Penerbit Star Gate Publisher. Riau.

Witjaksono, A. 2013. Akutansi Biaya. Edisi Revisi. Graha Ilmu. Yogyakarta.

Pamungkas., Vera Afrianti. 2006. Evaluasi Akuntansi Pertanggungjawaban Sebagai Alat Bantu Manajemen Dalam Pengendalian Biaya. (Studi Kasus pada PT. Cahaya Buana Intitama). Jurnal Ilmiah Ranggagading. Vol. 6, No. 1, April 2006:7-13. Sekolah Tinggi Ilmun Ekonomi Kesatuan Bogor. Bogor. 